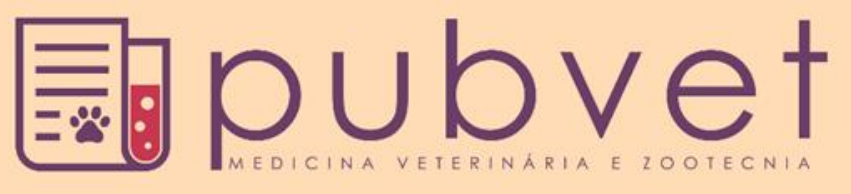

ISSN $1982-1263$

https://doi.org/10.31533/pubvet.v13n6a359.1-6

\title{
Enxerto ósseo na ortopedia veterinária: Revisão
}

\author{
Leonardo Lamarca de Carvalho ${ }^{1 *}$, Marina Laudares Costa $^{2}$, , Vanessa Yurika Murakami $^{1}$, Jessé Ribeiro \\ Rocha $^{30}$, Daniel Kan Honsho ${ }^{3 \theta}$, Lucas de Freitas Pereira ${ }^{3 \theta}$, Fernanda Gosuen Gonçalves Dias ${ }^{4} \theta$ \\ ${ }^{1}$ Discente do Programa de Pós-Graduação em Ciência Animal da Universidade de Franca - UNIFRAN, Franca - SP, Brasil, \\ ${ }^{2}$ Discente do Programa de Aprimoramento Profissional em Cirurgia e Anestesiologia de Pequenos Animais do Centro Universitário Barão de \\ Mauá, Ribeirão Preto - SP, Brasil. \\ ${ }^{3}$ Docente da Graduação em Medicina Veterinária da Universidade de Franca - UNIFRAN, Franca - SP, Brasil, \\ ${ }^{4}$ Docente do Programa de Pós-Graduação em Ciência Animal da Universidade de Franca - UNIFRAN, Franca - SP, Brasil \\ *Autor para correspondência, E-mail: e-mail: lamarca.leo@hotmail.com
}

Resumo. O crescente avanço da medicina veterinária e desenvolvimento de suas subáreas exigem o aprimoramento de métodos para o avanço das técnicas cirúrgicas e a realização de procedimentos especializados que reduzam complicações no pós-operatório, principalmente na ortopedia veterinária. Diante disso, o incremento das técnicas necessita de conhecimento prévio sobre a composição do tecido ósseo e de suas principais funções. Sabe-se que o tecido ósseo é composto por quatro tipos celulares, os osteoblastos, osteócitos, osteoclastos e células osteoprogenitoras, que são responsáveis pela formação, reparação e remodelagem do tecido. Atualmente, a utilização de enxertos ósseos vem sendo amplamente empregada, pois utilizam o tecido ósseo como a base da técnica, exercendo funções que estimulam a gênese de um novo tecido (tecido ósseo). Estes são de grande valia para o tratamento de fraturas cominutivas, artrodeses, exérese de tumores ósseos, osteomielite, má união e não união óssea e osteotomias corretivas, minimizando as chances de amputação do membro acometido. Uma gama de classificações é encontrada para descrever os tipos de enxertos ósseos e de acordo com sua origem, estes podem ser autógenos, alógenos, xenógenos e alopásticos e quanto a classificação estrutural, podem ser chamados de esponjosos, corticais, corticoesponjosos, dependendo do sítio doador. Cada enxerto possui características e funções distintas que devem ser avaliadas antes do processo de enxertia, para que melhor se adeque ao tipo de paciente. Sendo assim, o intuito do trabalho é descrever sobre os enxertos ósseos e suas aplicações na medicina veterinária.

Palavras-chave: enxertia, ortopedia, tecido ósseo

\section{Bone graft in veterinary orthopedics: Review}

Abstract. The increasing advance of veterinary medicine and the development of its subareas require the development of methods for the advancement of surgical techniques and the performance of specialized procedures that reduce postoperative complications, especially in veterinary orthopedics. In view of this, the increase of the techniques need prior knowledge about the composition of the bone tissue and its main functions. It is known that bone tissue is composed of four cell types, osteoblasts, osteocytes, osteoclasts and osteoprogenitor cells, which are responsible for the formation, repair and remodeling of the tissue. Currently, the use of bone grafts has been widely used, since they use the bone tissue as the basis of the technique, exerting functions that stimulate the genesis of a new tissue (bone tissue). These are of great value for the treatment of comminuted fractures, arthrodesis, exérese of bone tumors, osteomyelitis, bad union and not bone union, and corrective osteotomies, minimizing the chances of amputation of the affected limb. A range of classifications are found to describe the types of bone grafts, and according to their origin these may be autogenous, allogeneic, xenogens and allopathic, and as for structural 
classification, they may be called spongy, cortical, corticospinal, depending on the site donor. Each graft has distinct characteristics and functions that must be evaluated before the grafting process, so that it is better suited to the type of patient. Thus, the purpose of the paper is to describe the bone grafts and their applications in veterinary medicine.

Keywords: enxertia, orthopedics, bone tissue

\section{Injerto óseo en la ortopedia veterinaria: Revisión}

Resumen. El creciente avance de la medicina veterinaria y el desarrollo de sus subáreas exigen el perfeccionamiento de métodos para el avance de las técnicas quirúrgicas y la realización de procedimientos especializados que reduzcan complicaciones en el postoperatorio, principalmente en la ortopedia veterinaria. Frente a eso, el incremento de las técnicas necesita un conocimiento previo sobre la composición del tejido óseo y de sus principales funciones. Se sabe que el tejido óseo está compuesto por cuatro tipos celulares, los osteoblastos, osteocitos, osteoclastos y células osteoprogenitoras, que son responsables de la formación, reparación y remodelación del tejido. Actualmente, la utilización de injertos óseos viene siendo ampliamente empleada, pues utilizan el tejido óseo como la base de la técnica, ejerciendo funciones que estimulan la génesis de un nuevo tejido (tejido óseo). Estos son de gran valor para el tratamiento de fracturas conminutivas, artrodesis, exéresis de tumores óseos, osteomielitis, mala unión y no unión ósea y osteotomías correctivas, minimizando las posibilidades de amputación del miembro afectado. Una gama de clasificaciones se encuentra para describir los tipos de injertos óseos y de acuerdo con su origen, estos pueden ser autógenos, alógenos, xenógenos y alopáticos y en cuanto a la clasificación estructural, pueden ser llamados esponjosos, corticales, corticoespuestos, dependiendo del sitio donante. Cada injerto tiene características y funciones distintas que deben ser evaluadas antes del proceso de injerto, para que mejor se adecue al tipo de paciente. Siendo así, la intención del trabajo es describir sobre los injertos óseos y sus aplicaciones en la medicina veterinaria.

Palabras clave: injerto, ortopedia, tejido óseo

\section{Introdução}

A ortopedia veterinária busca melhoria das técnicas e a criação de materiais que possam auxiliar nas formas de tratamento e na rápida regeneração do tecido através da sua intensa atividade celular. Algumas alternativas terapêuticas vêm sendo empregadas visando o aproveitamento das funções ósseas e a redução das chances de complicações, resultando em significativa regeneração óssea e retorno as funções normais do paciente (Piermatei \& Flo, 1997).

Para o incremento das técnicas é necessário conhecimento sobre a composição do tecido ósseo e de suas principais funções. Sendo assim, sabe-se que este tecido é composto por quatro tipos celulares. Os osteoblastos são células encarregadas pela secreção da matriz óssea extracelular e sofrem progressão até o endurecimento da matriz, após isso, atingem a fase matura e passam a ser chamados de osteócitos. Estes, por sua vez, realizam a síntese e absorção da matriz óssea, fazendo manutenção do tecido ósseo e os osteoclastos são responsáveis pela absorção óssea. Já as células osteoprogenitoras são células de reserva, presentes no periósteo e endósteo e, que quando estimuladas, são precursoras dos osteoblastos, exercendo papel fundamental na regeneração óssea (Junqueira \& Carneiro, 2013).

Neste contexto, a utilização de enxertos ósseos vem sendo amplamente empregada, pois exercem funções que estimulam a gênese de um novo tecido (tecido ósseo). A enxertia estimula a atividade celular contínua, atividades metabólicas, físicas e humorais, levando aos processos de reparação e remodelação óssea de forma rápida. Estes são de grande valia para o tratamento de fraturas cominutivas, artrodeses, exérese de tumores ósseos, osteomielite, má união e não união óssea e osteotomias corretivas, minimizando as chances de amputação do membro acometido. Sendo assim, o intuito do presente trabalho é descrever sobre os enxertos ósseos e suas aplicações na medicina veterinária (Maimaitiyiming et al., 2015; Morato et al., 2017; Piermatei \& Flo, 1997). 


\section{Revisão de literatura}

O primeiro registro da aplicação de enxerto ósseo foi realizado em 1668 por um Holandês chamado Van Meeken, que resolveu retirar um fragmento ósseo do crânio de um cão e implanta-lo no de um soldado russo, observando sucesso na aplicação da técnica. Porém, devido à crença religiosa e ausência do conhecimento científico da época, Van Meeken foi obrigado a desfazer a implantação do enxerto, para evitar sua excomunhão da igreja Católica (Weigel, 1993). Já na medicina veterinária, o relato da primeira aplicação bem sucedida foi em 1976, por Wadsworth e Henry, que utilizaram dois enxertos corticais, um fresco e outro congelado, para a implantação em dois felinos, que mais tarde apresentaram cura óssea significativa (Alexander, 1987; Wadsworth \& Henry Junior, 1976).

Com o avanço da técnica e novas tentativas, alguns fatores foram associados ao sucesso das implantações de enxertos ósseos. Dentre eles, sabe-se que a osteogênese é o processo responsável pela formação do tecido ósseo por si só, através da ação de algumas células vivas (osteoblastos, osteócitos e osteoclastos) presentes no tecido doador, que irão permanecer no local até a revascularização do defeito. Outro fator, chamado de osteoindução é responsável por gerar o tecido propriamente dito, pois é ele que estimula a atividade das células osteogênicas e induz a proliferação de células pluripotentes a se diferenciarem em condrócitos e células osteogénicas, e que mais tarde iram originar o calo ósseo. Neste sentido, a osteocondução predispõe o crescimento dos capilares sanguíneos e de algumas células que também favorecem o processo de formação e dão suporte ao novo tecido ósseo (Dias et al., 2013). Por último, o processo chamado osteointegração consiste na conexão entre o sítio doador e o receptor, trazendo estrutura e funcionalidade semelhante ao do tecido original (Gerona, 2017). Cada enxerto possui características e funções distintas que devem ser avaliadas antes do processo de enxertia, para que melhor se adeque ao tipo de paciente. Atualmente, uma gama de classificações é encontrada para descrever os tipos de enxertos ósseos, e de acordo com sua origem estes podem ser denominados de autógenos, alógenos, xenógenos e alopásticos.

Os enxertos autógenos ou auto-enxerto utilizam o mesmo indivíduo como doador e receptor do tecido, diminuindo a ocorrência de rejeições e contribuindo para a formação de um novo tecido ósseo. Sua grande capacidade osteogênica, o torna um dos melhores tipos de implantes e o considera o padrãoouro dos enxertos. Devido à presença de células osteogênicas, matriz óssea, proteínas e por dar suporte ao crescimento ósseo, leva a remodelação e reparação do tecido através da osteogênese, osteoindução e osteocondução. No entanto, por se tratar do mesmo indivíduo, algumas desvantagens devem ser consideradas, como a exposição prolongada do paciente ao procedimento anestésico-cirúrgico (coleta e implantação) e o risco de infecções pela maior exposição do leito (Campana et al., 2014; Nandi et al., 2010). Em estudo realizado por Kim et al. (2009), os pesquisadores demostraram por meio de questionários, a presença de dor pós-operatória em pacientes submetidos ao processo de enxertia óssea autógena, tendo como sítio doador a crista ilíaca, em que 1 ano após a realização dos procedimentos $15,1 \%$ dos pacientes apresentaram dor na região doadora durante a realização de caminhadas, $14,1 \%$ dificuldade em realizar atividades domésticas e $29,1 \%$ apresentaram dormência na região do leito doador. Desta forma, o estudo demonstrou que apesar de ser considerado o padrão ouro das enxertias e reduzir o número de rejeições, a dor pós-operatória pode estar presente nos humanos e causar debilidade nos pacientes submetidos ao procedimento.

Os enxertos alógenos, também conhecidos como homógenos ou homoenxertos são adquiridos a partir de um indivíduo e enxertados em outro da mesma espécie. Neste caso, os enxertos não são utilizados na forma fresca e passam por processamento e preparação, visando a redução do número de células e, consequentemente, das reações imunológicas e do número de partículas geradoras de infecções. Os homoenxertos não possuem capacidade osteogênica semelhante ao auto-enxerto e suas atividades osteoindutoras e osteoconduras dependem do tipo de processamento realizado (desmineralizado, liofilizado ou fresco congelado). Por utilizar distintos indivíduos, apresenta como vantagem a possibilidade da realização de um banco de ossos, facilitando sua disponibilidade, moldagem, tamanha e quantidade de material, principalmente em casos emergências (Alievi et al., 2007; Goldberg, 1992; Oliveira et al., 2007)

Os xenoenxertos, xenógenos, heterológos ou heteroenxertos são obtidos de um indivíduo e inseridos em um paciente de outra espécie. Estes são inorgânicos e necessitam da realização de processamento 
para sua aplicação, por também possuir grande capacidade imunológica, já que os indivíduos são geneticamente diferentes. O uso de enxertos heterológos, de origem bovina, vem sendo comumente empregado na medicina, por conter características ósseas de porosidade, composição, tamanho, forma e comportamento fisiológico semelhante às reações ósseas humanas. Neste sentido, seu emprego na medicina veterinária tem ganhado credibilidade, por ser de fácil aquisição (Galia et al., 2005; Moraes et al., 2005).

Os enxertos aloplásticos são confeccionados por meio de materiais inorgânicos ou sintéticos e podem ser classificados de acordo com o comportamento biológico em bioativos, bioenertes, biotoleráveis e reabsorvíveis. Aqueles denominados como bioativo são materiais que possuem ligações iônicas com cálcio e fósforo, que estimulam a proliferação óssea. Os bioinertes são matérias que no seu âmbito não levam a alterações orgânicas onde foi implantado e os biotolerados induzem a formação pelo organismo, de uma cápsula ao seu redor para impedir reações do tecido hospedeiro. E por último, a reação biológica absorvível, uma estrutura que será degradada e consequentemente trocada pelo tecido original onde foi implantado (Gutierres et al., 2005).

Para a confecção dos materiais bioativos, três matérias podem ser encontradas (fosfato tri-cálcico, sulfato de cálcio e vidro bioativo). A primeira, denominada de hidroxiapatita, é um material natural considerado fosfato de cálcio hidrato, presente nos vertebrados, compondo o esqueleto ósseo. Atua como reserva de cálcio e fósforo, conservando a estrutura mineral do osso. Além disso, tem como principal característica a osteocondutividade, promovendo o crescimento ósseo no interior do enxerto, levando a estabilidade e manutenção do implante (Ripamonti, 1996). A segunda matéria é considerada uma cerâmica de baixo custo, de fácil aquisição, reabsorvível, biocompatível e osteocondutiva, devendo estar associada a outros componentes enxertivos (osso autógeno, alógeno, polímero ou a hidroxiapatita). Sua principal função é preencher defeitos ósseos, levando a osteocondunção, remodelação das estruturas a serem formadas e manter os atributos anatômicos e estruturais do local em que foi implantado. Porém, seu uso torna-se limitado já que ocorre perda das funções mecânicas assim que seu processo de degradação é instalado (Tay et al., 1999). O terceiro é considerado um material compatível biologicamente, podendo conter em sua composição sílica, óxido de sódio, óxido de cálcio e fosfatos. Estudos demonstraram que sua ação promove a divisão e o crescimento celular em culturas, não gerando reações inflamatórias, e sua ação está relacionada à sua composição, $\mathrm{pH}$, temperatura e porosidade do vidro, que influenciam diretamente na deposição do novo tecido a ser formado (Gutierres et al., 2005; Nandi et al., 2010; Trevisan Júnior et al., 2006).

Quanto à classificação estrutural, os enxertos ósseos podem ser denominados de esponjosos, corticais, corticoesponjosos, dependendo do sítio doador. O enxerto esponjoso tem origem do osso trabecular, geralmente retirado da região metafisária dos ossos longos, como a metáfise proximal do úmero. Devido à porosidade do enxerto, este é reconhecido como facilitador da proliferação óssea pela migração de vasos e células, sendo necessário escolher o local de retirada deste com maior disponibilidade óssea (Santos \& Rahal, 2004; Weigel, 1993). O enxerto cortical é coletado da região diafisária dos ossos longos, podendo ser mantido fresco ou conservado em bancos de ossos. Devido sua arquitetura, permite maior suporte estrutural, tendo sua aplicação mais indicada para fraturas cominutivas e exérese óssea por tumor (Alexander, 1987; Kaveh et al., 2010). Os corticoesponjosos possuem área cortical e esponjosa, apresentando as funções de cada subtipo ósseo, ou seja, suporte estrutural do enxerto cortical e a facilitação de suprimento sanguíneo do enxerto esponjoso.

Os enxertos também podem ser classificados de acordo com sua forma de apresentação, ou seja, em bloco ou particulado. Os enxertos em bloco são retirados do leito doador inteiro e passam pelo processamento no mesmo formato, e apenas na sua aplicação são moldados de acordo com a necessidade e dependem de uma estabilização (Scarso Filho et al., 2001). Já o particulado, passa pelo processo de trituração e assim é aplicado no sítio receptor. Este último geralmente é preferido devido à facilidade de neovascularização entre os fragmentos triturados (Schou et al., 2000).

De acordo com os métodos de esterilização e conservação dos enxertos, destaca-se o congelamento, um método capaz de preservar as funções biomecânicas e osteoindutivas, além de diminuir significativamente as reações imunogênicas, sendo de fácil processamento. No entanto, sua capacidade de conservação não evita a transmissão de agentes infecciosos (Oliveira et al., 2007). A liofilização consiste no processo de congelamento do osso a $-76^{\circ} \mathrm{C}$ e manutenção da peça em liofilizador comercial, 
para posteriormente ser submetido ao vácuo até que a temperatura atinja $20^{\circ} \mathrm{C}$ e umidade de $5 \%$. Após o processamento são mantidos em embalagens a vácuo em temperatura ambiente (Bojrab, 2005). A autoclavagem consiste na exposição do enxerto a temperatura de $127^{\circ} \mathrm{C}$ durante 15 minutos, removendo grande parte da imunogenicidade e levando a coagulação sanguínea, desnaturação de proteínas e colágeno ósseo, resultando em falhas na revascularização e perda da função osteocondutoras (Giordano \& Almeida, 2006). Já a conservação em glicerina $98 \%$, é um processo longo que consiste na imersão do enxerto por no mínimo 28 dias para que ocorra inatividade imunogênica e controle das contaminações, sem prejudicar as funções onteoindutoras e osteocondutoras. Em contrapartida, há necessidade de reidratação no pré-operatório, já que a desidratação leva ao ressecamento do osso e consequentemente fragilidade do implante (Ziliotto et al., 2003). O óxido de etileno consiste na esterilização óssea através do desengorduramento, desidratação (álcool absoluto) por 48 horas e exposição ao óxido. Estudos demonstraram que este método altera as propriedades mecânicas de tensão, deformação e elasticidade, devendo ser evitado em locais que sofram grandes cargas (Ziliotto et al., 2003). O mel é considerado bom conservador ósseo, eficaz contra reações imunológicas, de baixo custo e facilmente encontrado. Porém, cuidados devem ser tomados quando a sua utilização, como por exemplo, a exposição à luz solar e altas temperaturas que prejudicam suas funções antimicrobianas e antibacterianas (Ferreira et al., 2012).

Neste contexto, a utilização dos enxertos visa a correção dos defeitos ósseos e rápido retorno as funções normais do paciente. Cada qual possui funções distintas e estudos devem ser realizados para determinar qual tipo de enxerto melhor se adeque a situação. Atualmente, apesar da elevada quantidade de estudos realizados com utilização dos autoenxertos (padrão ouro), homoenxertos e heteroenxertos, novos estudos devem ser realizados para que outros tipos de enxertos possam ser aplicados na rotina ortopédica, mormente na veterinária. Neste sentido, o uso dos enxertos aloplásticos pode ser considerado como opção para o tratamento das disfunções ósseas em animais, pois visam a facilidade de aplicação e podem reduzir consideravelmente as alterações de origem imunológica.

\section{Referências bibliográficas}

Alexander, J. W. (1987). Bone grafting. The Veterinary Clinics of North America. Small Animal Practice, 17(4):811-819.

Alievi, M. M., Schossler, J. E. W., Guimarães, L. D. G., Oliveira, A. N. C., Traesle, C. K. \& Ferreira, P. A. (2007). Implante ósseo cortical alógeno conservado em mel na reconstrução de falha óssea diafisária em fêmur de cães: avaliação clínica e radiográfica. Ciência Rural, 37(2).

Bojrab, M. J. (2005). Técnicas atuais em cirurgia de pequenos animais. São Paulo: Editora Roca.

Campana, V., Milano, G., Pagano, E., Barba, M., Cicione, C., Salonna, G., . . Logroscino, G. (2014). Bone substitutes in orthopaedic surgery: from basic science to clinical practice. Journal of Materials Science: Materials in Medicine, 25(10):2445-2461.

Dias, I. R., Sousa, C. M. P., Carvalho, P. M. P., Lempeck, M. R., Viegas, C. A. \& Azevedo, J. T. (2013). Enxertos e substitutos ósseos em cirurgia ortopédica reconstrutiva nos animais de companhia: uma breve revisão. Revista Brasileira de Medicina Veterinária, 35(4):339-350.

Ferreira, M. P., Alievi, M. M., Beck, C. A. C., Dal-Bó, I. S., Gonzalez, P. C., Nóbrega, F. S., . . Rocha, J.P. V. (2012). Comparison of lyophilization, and freezing in honey as techniques to preserve cortical bone allografts used to repair experimental femoral defects in domestic adult cats. Arquivo Brasileiro de Medicina Veterinária e Zootecnia, 64(2):263-273.

Galia, C. R., Rosito, R., Mello, T. M. \& Macedo, C. A. S. (2005). Uso de enxerto ósseo homólogo e heterólogo em diáfise femoral de ratos: comparação entre enxerto ósseo congelado e liofilizado. Revista Brasileira de Ortopedia, 40(3):141-146.

Gerona, B. I. (2017). Influência da modificação da superfície implantar na osteointegração dos implantes dentários. Master of Science, Instituto superior de ciências da saúde, Egas Moniz, Almada, Portugal.

Giordano, P. P. \& Almeida, A. J. P. (2006). Enxertos ósseos: revisão de literatura. Doxo Revista da Puc Minas, 1(1):1-9.

Goldberg, V. M. (1992). Natural history of autografts and allografts Bone implant grafting. London, UK: Springer. 
Gutierres, M., Lopes, M. A., Hussain, N. S., Cabral, A. T., Almeida, L. \& Santos, J. D. (2005). Substitutos ósseos: conceitos gerais e estado actual. Arquivos de Medicina, 19(4):153-162.

Junqueira, L. C. \& Carneiro, J. C. (2013). Histologia Básica (12 ed. ed.). Rio de Janeiro: Guanabara Koogan.

Kaveh, K., Rashid, I., Mohd, Z. \& Tengku, A. I. (2010). Bone grafting and bone graft substitutes. Journal of Animal and Veterinary Advances, 9(6):1055-1067.

Kim, D. H., Rhim, R., Li, L., Martha, J., Swaim, B. H., Banco, R. J. \& Tromanhauser, S. G. (2009). Prospective study of iliac crest bone graft harvest site pain and morbidity. The Spine Journal, 9(1):886-892.

Maimaitiyiming, A., Amat, A., Rehei, A., Tusongjiang, M. \& Li, C. (2015). Treatment of the femoral shaft nonunion with double plate fixation and bone grafting: A case series of 14 patients. Injury, 46(6):1102-1107.

Moraes, P., Selmi, A., Padilha Filho, J. G. \& Canola, J. C. (2005). Utilização de enxerto cortical de ave (gallus gallus domesticus-linnaeus, 1758) na reparação de ostectomia diafisária femoral em gato. Ars Veterinaria, 21(4):129-134.

Morato, G. O., Rocha, A. G., Chung, D. G., Moraes, P. C. \& Padilha Filho, J. G. (2017). Enxertos ósseos em medicina veterinária. Investigação, 16(1):1-5.

Nandi, S. K., Roy, S., Mukherjee, P., Kundu, B., De, D. K. \& Basu, D. (2010). Orthopaedic applications of bone graft \& graft substitutes: a review. Indian Journal of Medical Reseach, 132(1):15-30.

Oliveira, A. C. P., Collares, M. V. M., Galia, C. R., Edelweiss, M. I., Pinto, R. D. A. \& Knebel, L. (2007). Comparação entre enxerto ósseo autólogo, homólogo congelado e homólogo liofilizado em modelo experimental de cranioplastia. Revista Brasileira de Cirurgia Craniomaxilofacial, 10(4):140-146.

Piermatei, D. L. \& Flo, G. L. (1997). Boné Grafting. Philadelphia, USA: W.B. Saunders.

Ripamonti, U. (1996). Osteoinduction in porous hydroxyapatite implanted in heterotopic sites of different animal models. Biomaterials, 17(1):31-35.

Santos, F. C. \& Rahal, S. C. (2004). Enxerto ósseo esponjoso autólogo em pequenos animais. Ciência Rural, 34(6):1969-1975.

Scarso Filho, J., Barreto, M. A. \& Tunes, U. d. R. (2001). Planejamento estético cirúrgico e protético em implantodontia.

Schou, S., Pallesen, L., Hjørting-Hansen, E., Pedersen, C. S. \& Fibæk, B. (2000). A 41-year history of a mandibular subperiosteal implant. Clinical Oral Implants Research: Case report, 11(2):171-178.

Tay, B. K. B., Patel, V. V. \& Bradford, D. S. (1999). Calcium sulfate-and calcium phosphate-based bone substitutes: mimicry of the mineral phase of bone. Orthopedic Clinics, 30(4):615-623.

Trevisan Júnior, W., Rodrigues, M. R., Silva, T. B. \& Simioni, J. C. (2006). Sulfato de cálcio como barreira e material de preenchimento associado ao osso autógeno no tratamento de defeito ósseo periodontal-Proposta de tratamento e relato clínico. Innovations Implant Journal Biomaterials and Esthetics, 1(1):54-61.

Wadsworth, P. L. \& Henry Junior, W. B. (1976). Entire segment cortical bone transplant. Journal of the American Animal Hospital Association, 12(6):741-745.

Weigel, P. J. (1993). Bone grafting. In J. M. Bojrab (Ed.), Disease mechanisms in small animal surgery (pp. 678-685). Philadelphia, USA: Lea \& Febiger.

Ziliotto, L., Daleck, C. R., Padilha Filho, J. G., Souza, A. P., Fantinatti, A. P. \& Diniz, P. P. V. P. (2003). Utilização de implante ósseo cortical alógeno conservado em glicerina para preservação de membro torácico: estudo experimental em cães. Acta Cirúrgica Brasileira, 18(2):107-115.

Recebido: 28 de abril, 2019.

Aprovado: 25 de maio, 2019.

Publicado: 3 de julho, 2019.

Licenciamento: Este artigo é publicado na modalidade Acesso Aberto sob a licença Creative Commons Atribuição 4.0 (CCBY 4.0), a qual permite uso irrestrito, distribuição, reprodução em qualquer meio, desde que o autor e a fonte sejam devidamente creditados. 